\title{
Mirar y obedecer: la estética autoritaria del nuevo edificio legislativo
}

\author{
Laura Flores-Valle * \\ https://orcid.org/0000-0003-0996-7755
}

Está registrado que aun los antiguos egipcios levantaban los obeliscos macizos de la historia cincelados en bloques de granito hecho de arena movediza de mitos (expuesta a la presión del tiempo). Después de todo, es una costumbre que se ha preservado hasta nuestros tiempos... — Goran Petrovic

Si bien entre nosotros casi no se habla de otra cosa que de conejos, en realidad nunca hemos visto uno. Dudamos incluso de su existencia. En nuestras conversaciones el conejo oficia de metáfora, o de símbolo. Es frecuente observar que muchos, una gran mayoría, hemos olvidado la primitiva significación de la palabra, incluso si es que ha tenido alguna, alguna vez.

- Mario Levrero

\section{Resumen}

El nuevo edificio de la Asamblea Legislativa y los demócratas ejemplares son el punto de partida para reflexionar sobre la geometría del poder y cómo esta se expresa y materializa en el espacio construido de la ciudad de San José. En el presente ensayo $^{1}$ se propone que el nuevo edificio legislativo, en tanto objeto inmerso en un espacio y una época, evoca una praxis muy específica de la democracia y fue conscientemente diseñado a partir de un principio fundamental: el miedo al Otro. Se argumenta que, contrariamente a las narrativas oficiales, el diseño refuerza una idea vertical del poder y, lejos de representar transparencia y solidez, es una estructura que promueve activamente la despolitización del espacio público, la higienización de las conductas y el disciplinamiento de la mirada, todo muy a tono con el ethos policiaco y punitivo de la época.

Palabras clave: Arquitectura, desigualdad, identidad, poder, segregación espacial.

* Licenciada en Filología Española de la Universidad de Costa Rica. Editora de la Revista Nacional de Cultura de la Universidad Estatal a Distancia y correctora de estilo independiente. Correo: lfloresv@uned.ac.cr / La autora hace un agradecimiento especial al arquitecto Luis Flores Castro, lúcido interlocutor en temas de política y arquitectura.

\footnotetext{
${ }^{1}$ Aprobado por el comité editorial de la Revista Espiga en sesión del 14 de mayo de 2021. La sección en que se publica no es arbitrada mediante el proceso de pares. El artículo fue publicado originalmente en la revista digital El Fígaro.
} 


\section{A manera de introducción}

Enhiesto. El término, antiguo como la guerra, hijo del latín 'infestus', remite a todo aquello que es 'derecho, hostil y dirigido contra alguien'. Se dice que esta palabra, moldeada en los engranajes más antiguos del universo militar, está directamente vinculada a las lanzas (jabalinas) y al gesto de levantarlas y ponerlas en posición hostil -oblicuas u horizontales- para luchar contra el enemigo, es decir, contra la barbarie.

Enhiesto y viril como esas fálicas jabalinas, el nuevo edificio legislativo se yergue en la achatada geografía de una capital que se ha desparramado hacia los cuatro costados de sí misma, sin planificación ni complejos. Se eleva, la enhiesta mole de concreto, con la misma soberbia de ciertos demócratas -todos ellos ejemplares-que iluminan con su verbo y su prosa la sombría decadencia de la política y la prensa nacional.

El espíritu que palpita en los cimientos del edificio legislativo y en el alma de los demócratas ejemplares, esos enemigos declarados de la barbarie, es, a final de cuentas, muy similar: disciplinar a la ciudadanía en una idea muy específica de lo que hemos de entender por democracia $\mathrm{y}$, por supuesto, adiestrarnos en las convenciones respecto a cómo debemos comportarnos en ella.

El disciplinamiento es necesario, sin lugar a duda: es consustancial al pacto democrático, ese acuerdo civilizatorio que nos aleja de los abismos dictatoriales y otras derivas políticas. Sin embargo, afirmar lo anterior no implica perder de vista algo igualmente importante: así como los consensos que sustentan la democracia exigen diálogo, negociación y pactos de toda naturaleza, requieren también de una depurada puesta en escena, una puesta en escena dentro de la cual el nuevo edificio de la Asamblea Legislativa y los discursos de los demócratas ejemplares son parte fundamental. Ambos, edificio y demócratas ejemplares, son los pilares de una geometría del poder sobre la cual, aunque sea de vez en cuando, vale la pena detenerse a pensar.

\section{La geometría como expresión de la política}

Los edificios, como hechos materiales y estéticos, encarnan una política, una organización particular del mundo y de las relaciones humanas que se producen dentro, alrededor y a partir de ellos. No es posible leerlos como hechos aislados, como las inocuas ocurrencias de arquitectos e ingenieros. Los edificios son mucho más que piedra; los edificios son siempre, o casi siempre, carne y sacrificio.

Los demócratas ejemplares, por su parte, cumplen diversos roles, pero uno de los más importantes es el de ser los portavoces acreditados de la democracia. No solo dictaminan, con sutiles mecanismos o vehementes discursos, los márgenes de lo tolerable y lo intolerable, sino que erigen los edificios del sentido en medio del caos, y construyen, así, un mundus, un ombligo desde donde trazan los ejes de lo deseable y lo indeseable.

Eso mismo hacen las firmas de arquitectura, las empresas constructoras y las inmobiliarias: construyen artefactos que se insertan en el territorio, modificándolo profundamente, y al hacerlo sacralizan formas de relacionarse con el entorno y con la realidad. Dichos procesos constructivos -inevitables y necesarios- toman años, pero son, para quienes los viven en carne propia, profundos e irreversibles. 
Los edificios imponen formas de circulación, de consumo y de socialización, y por eso mismo deberían empujarnos a pensar ciertos asuntos de vital importancia, entre ellos: a) la sensación que nos produce el mero hecho de observarlos o circular en ellos; b) las relaciones espaciales que, en tanto edificios (pensemos en el de la Asamblea o cualquier otro), establecen con el entorno, y c) de qué modo intervienen en la transformación o perpetuación de ciertas relaciones (de clase y poder) en un determinado espacio y momento histórico.

Además de todo lo anterior (que no es poco), los edificios -y particularmente cualquier inmueble cuyo financiamiento y mantenimiento dependa de recursos públicos y fideicomisos otorgados por bancos estatales- debería motivarnos a reflexionar concienzudamente sobre la impronta histórica que las firmas de arquitectos y las empresas constructoras dejan en los territorios que habitamos y en las ciudades y los sistemas económicos que padecemos:

El nuevo edificio de la Asamblea Legislativa es una cosa intelectual; es un edificio muy intelectual. Para poder entenderlo hay que estudiarlo y verlo y sentirlo. Yo creo, como arquitecto, que la arquitectura no hay que hablarla. A mí me dicen que es un mamotreto y a mí me entra por aquí y me sale por aquí. El edificio va a permitir que los diputados crezcan, porque esto es un santuario. O sea, vean este plenario, este plenario es una cosa que se diseñó... van a verlo acabado: ¡es una iglesia, es un santuario para la democracia! ${ }^{2}$

Lo que pretendo a través de las siguientes líneas, muy a contrapelo de lo dicho por el arquitecto Salinas, es hablar la arquitectura (sic) y embarcarme en algo absurdo: comparar el nuevo edificio de la Asamblea Legislativa (ese portentoso inmueble, «ese santuario de la democracia») con un sujeto social específico: el demócrata ejemplar. Acercarme, pues, a la piedra y a la carne de la democracia costarricense en un momento (el bicentenario) especialmente atravesado por fervores cívicos de todo tipo.

\section{¿De qué manera la piedra se convierte en carne?}

Con ceremonias religiosas y cápsulas enterradas, la actual Asamblea Legislativa ha hecho un esfuerzo consciente por cumplir al pie de la letra lo dicho por Jorge Salinas y se ha esmerado por convertir el nuevo edificio en un espacio ceremonial dignificado, en donde los observadores nos vemos obligados y obligadas, como en el foro romano, a «hacer el bien o a actuar de esa manera» ${ }^{3}$ :

Es simbólico que estén [enterrados] la Biblia, la Constitución Política y el Reglamento; los tres elementos esenciales que un diputado asume respetar y creer, y que son simbólicos, también, de los valores costarricenses. Costa Rica está fundada por valores judeocristianos y pensamos que es importante el tema de que estén la Biblia y la Constitución Política y el Reglamento.

Estas palabras, pronunciadas por el diputado Gonzalo Ramírez (el presidente del directorio legislativo cuando se colocó la primera piedra del proyecto, en 2017), nos recuerdan algo fundamental: el nuevo edificio aspira, desde su base, a lo sagrado, y la forma de hacerlo es elevándose, ajeno al barullo externo, y manteniendo a raya

\footnotetext{
2 Declaraciones brindadas por Jorge Salinas, el arquitecto encargado del diseño, a Noticias Repretel, en febrero de 2019.

${ }^{3}$ Richard Sennett, Carne y piedra. El cuerpo y la ciudad en la civilización occidental (Madrid: Alianza Editorial, 2019), 79.
} 
todas aquellas conductas que atenten contra el orden democrático, que es imaginado como algo sagrado, pulcrísimo, incorruptible. El edificio aspira a cumplir con la profecía que Salinas, en un febril arrebato de misticismo religioso, lanzó desde un inicio: ser un «santuario para la democracia».

Agreguemos a esto último lo dicho por Ricardo Ayales, director ejecutivo de la Asamblea Legislativa, quien en entrevista con un canal de televisión nacional señalaba que una de las grandes ventajas del nuevo edificio legislativo era su diseño antihuelgas y sus paredes antigrafitis ${ }^{4}$.

El ethos policiaco y punitivo de nuestra época se despliega con toda naturalidad en un edificio que fue conscientemente diseñado para sofocar y neutralizar el disenso, para eliminar cualquier acto que signifique una amenaza concreta (o imaginaria) a la democracia, ese mito encarnado, para bien y para mal, en la carne y en la piedra. En la carne de las personas diputadas, en su inmunidad, sus privilegios y su miedo a ser encarados o increpados públicamente; y en la piedra: en las impolutas paredes de un edificio que, totalmente replegado sobre sí mismo, parece negar el entorno que lo rodea.

Se ha repetido hasta la saciedad, siguiendo lo dicho por el arquitecto Salinas, que en el nuevo edificio legislativo las personas diputadas están ubicadas «más abajo del pueblo al que deben obedecer», pero ese no es más que un velo retórico para ocultar lo evidente: a las personas diputadas les ha sido deliberadamente negada la posibilidad de establecer cualquier tipo de contacto visual con la gente que asiste a las barras, esa masa informe que, desde un cajón de cristal ubicado más arriba, termina convertida en una abstracción, en un murmullo inaudible. Las personas que asisten a las barras son borradas de la vista de las personas diputadas gracias a un diseño que, al anular cualquier posibilidad de contacto, refuerza algo muy importante: la idea de verticalidad.

De hecho, es muy llamativo que el reclamo por esta situación haya salido de las mismas personas diputadas, quienes luego de mudarse al nuevo edificio han expresado que están metidas en un búnker ${ }^{5}$ y que «les ha sido objetivamente negado el contacto con la prensa y la ciudadanía».

La brecha espacial entre personas diputadas y personas ciudadanas es, sin duda, muy congruente con las dinámicas espaciales que se producen en la ciudad de San José y, en mayor medida, en la Gran Área Metropolitana. No hay que olvidar que en el espacio construido -especialmente en aquello que entendemos como espacio público-, es donde suelen manifestarse y experimentarse, con sutileza o con extrema violencia, las desigualdades sociales más profundas.

\footnotetext{
${ }^{4}$ Paula Ruiz, «Nuevo edificio legislativo está resguardado con material antigrafitis y póliza contra vandalismo», Observador.cr, 25 de octubre del 2020, acceso: 30 de octubre del 2020, $\mathrm{https}$ //observador.cr/domingo-nuevo-edificio-legislativo-esta-resguardado-con-material-antigrafiti-ypoliza-contra-vandalismo/

${ }^{5}$ Fabiola Pomareda, «Remueven láminas de zinc que rodeaban nuevo edificio de la Asamblea Legislativa», Semanario Universidad, 18 de enero del 2021, acceso: 19 de enero del 2021, https://semanariouniversidad.com/pais/remueven-latas-de-zinc-que-rodeaban-nuevo-edificio-de-laasamblea-legislativa/
} 




Panorámica del nuevo edificio de la Asamblea Legislativa desde la Plaza de la Democracia. Fotografía de Mauricio Inostroza.

Recordemos, también, que nuestro país ha construido su identidad negando el conflicto y aferrándose a narrativas que sofocan las profundas contradicciones y luchas sociales que le han dado forma a nuestro territorio y a nuestra historia. Dicha negación ha permitido sacralizar la idea de la excepcionalidad costarricense, que, ligada a valores como el diálogo, la resolución pacífica de los conflictos, la ausencia de ejército y la presencia del país en ciertas clasificaciones internacionales de renombre, nos convierte, por supuesto, en «ave rara» y ejemplo para Centroamérica y el resto del universo conocido (y por conocer).

Este edificio de 21 pisos es una prueba más de los enormes esfuerzos -económicos y simbólicos- que se hacen para: a) seguir elevando el mito y b) mantener a raya el conflicto. Nos demuestra, de forma muy concreta, que estamos dispuestos a pagar lo que sea necesario para mantener a flote una adecuada puesta en escena y que existen delicados mecanismos para barrer del territorio cualquier gestualidad política que transgreda los códigos establecidos con tanto esfuerzo. Todo ello, está claro, se hace en procura de resguardar algo importante: los principios e ideales que han hecho de nuestro país una de las democracias más estables y antiguas de América Latina.

La democracia, ya se sabe, es un sistema político que descansa sobre ciertos principios, pero es también una representación ritualizada de la que todas las personas participamos. El ritual de lo democrático, absolutamente necesario para imaginar una comunidad de sentido y un destino común, se expresa a la perfección en la imagen de un público que, desde las barras de la nueva Asamblea y separado del plenario legislativo, puede escuchar lo que discuten las personas diputadas a través de pantallas y demás dispositivos de última tecnología, pero no puede hacerse escuchar. El diseño replica una dinámica a la que estamos muy acostumbrados: la de opinar con una pantalla o un vidrio de por medio. Opinar, claramente, no es incidir en la materialidad que nos rodea. 
La interacción verbal o visual ha sido convenientemente anulada. De igual modo, el sudor, el escándalo, los reclamos y las consignas de quienes vayan a protestar a la Asamblea Legislativa (la corporalidad y la palabra de los manifestantes) quedarán ahogadas en la calculada inaccesibilidad de una portentosa estructura.

Dicho de otro modo, el malestar social -el deseo que hace existir lo político-, que históricamente suele expresarse a través de marchas y concentraciones en las calles aledañas a la Asamblea, ha sido oportunamente expulsado del ángulo de visión de «los padres y las madres de la patria». Se procura, de ese modo, «higienizar» el espacio, y quizás más importante aún, los comportamientos.

Sin embargo, creo que no todo es ceguera e indiferencia en la nueva casa de la democracia: a las personas diputadas les queda la opción de apretujarse a observar las manifestaciones desde las celosías desperdigadas aquí y allá; esos alargados conductos que, se supone, ayudarán a ventilar al edificio y salvarlo de su propio encierro.

El diseño del edificio legislativo es la materialización de una serie de imperativos estéticos e ideológicos. Los azulejos, las paredes limpísimas, la asepsia de sus materiales: todo está pensando para lograr un determinado efecto en quien lo habita y quien lo observa. Las reglas de interacción entre personas diputadas y ciudadanía, entre personas diputadas y manifestantes, han sido preestablecidas y pautadas por quien diseña, en un ejercicio de poder atravesado por sus propias concepciones de lo que debe $-\mathrm{o}$ debería - ser la «casa de la democracia» y, por añadidura, «la democracia».

De hecho, es muy interesante que el edificio responda a los ideales sostenibles de un siglo XXI avasallado por los grises augurios del cambio climático:

La nueva sede de la casa de la democracia tiene 21 pisos y cerca de 50 mil metros cuadrados. Cuenta con un diseño bioclimático y carbononeutral que optimiza el uso del vidrio para favorecer la demanda energética, disminuir las emisiones de $\mathrm{CO} 2$ y aumentar el confort término de los usuarios y, por ende, el uso de los aires acondicionados será sustancialmente menor. Es un edificio funcional, amigable con el ambiente y que cumple con los requerimientos de seguridad de una edificación moderna y prueba de ello es que cuenta con varias certificaciones, entre ellas, el sello azul en planos Bandera Azul de Construcción Sostenible y se está en el trámite para obtener la certificación Reset, en Edificios Sostenibles en el Trópico, con lo cual da un ejemplo de ahorro energético, además será el primer edificio en recibir una certificación por accesibilidad.

Amigable con el ambiente, accesible, confortable, sostenible: el edificio encaja perfectamente con la marca país ${ }^{6}$. El diseño encarna, simboliza, proyecta y reproduce todo aquello que, en teoría, nos distingue como nación. La «esencia» de Costa Rica queda de este modo expresada en una arquitectura totalmente «respetuosa» de los «valores costarricenses», valores que han sido debidamente certificados y catalogados como tales gracias a procesos discursivos avalados por diferentes instancias, entre ellas, por supuesto, los demócratas ejemplares, esa cofradía de iluminados caballeros llamados a proteger el cáliz de la democracia.

\footnotetext{
${ }^{6}$ «Marca esencial Costa Rica, Esencial Costa Rica», Esencial Costa Rica, acceso: 20 de octubre del 2020, https//www.esencialcostarica.com/marca-pais/que-es-la-marca-pais/
} 
No me parece exagerado afirmar que un bloque de concreto erecto e impoluto instruye e impone formas de imaginar y experimentar la realidad. De hecho, estoy convencida de que esa mole gris ejercerá, como tantas otras moles de cemento en nuestra capital, el continente y el mundo, un disciplinamiento de la mirada y, con ello, la interiorización de determinadas formas de circular y de estar.

Algo fundamental, en relación con todo esto, es subrayar que el edificio parece estar concebido desde la desconfianza y es, por eso mismo, totalmente afín a la sensibilidad individualista que caracteriza nuestra época, en donde el miedo (al Otro) y la fragilización de lo colectivo parecen ser el soporte de los desgastados vínculos sociales que mantienen en vilo al tejido social. La sintaxis propia del neoliberalismo queda exquisitamente impregnada en la estructura y en la apariencia de un edificio volcado sobre sí mismo, un enhiesto edificio que teme por su seguridad y hace lo propio para expulsar cualquier amenaza real o simbólica.

El edificio legislativo, de hecho, evoca el carácter cerrado de los condominios. Su férreo control del acceso, necesario para resguardar la seguridad de un espacio que alberga un poder de la República, está al servicio de una fantasía de impenetrabilidad secundada por un tipo de arquitectura que emerge por todas partes y responde a «un esquema de expansión urbana que dejó la tarea del desarrollo territorial en manos de las empresas 'urbanizadoras', las constructoras y las inmobiliarias» ${ }^{7}$.

Así pues, y aunque se diga lo contrario -aduciendo que hay un ventanal enorme en la fachada oeste de la estructura, celosías en todas las demás fachadas y un gran patio central que da luminosidad y transparencia a todo el conjunto-, la apariencia general del edificio y de esos 21 pisos, que se levantan hacia el cielo como un emblema de fuerza e inexpugnabilidad, nos recuerdan una especie de fortaleza.

Se trata, a grandes rasgos, de una fortificación cuidadosamente diseñada para evitar el desorden, el ruido y el disenso; una estructura que colabora activamente en la despolitización de los espacios circundantes.

Dice David Harvey ${ }^{8}$, citando a Whitehead, que incluso algo tan «sólido y perdurable como una pirámide egipcia se constituye de materia en movimiento. La dialéctica nos obliga, entonces, a plantear permanentemente la pregunta acerca de la 'cosa' o el 'evento' con que nos encontramos: ¿mediante qué proceso ha tomado forma y cómo se sostiene?» Estas preguntas, en el caso del edificio legislativo, pueden dar cabida a muchas respuestas, pero la lógica constructiva, creo yo, es elocuente: consiste en encerrar a las personas diputadas en el subsuelo y es, salvando las distancias -si es que las hay- similar a la que rige en los condominios en altura: habitar una guarida pulcra, moderna, insonorizada; es decir, un lugar autosuficiente y convenientemente arrancado de contexto, vaciado de vínculos con el exterior; un no lugar en donde, además de una serie de «amenidades» para satisfacer aspiraciones de comodidad, seguridad y estatus, estamos -y esto es lo principal- a salvo de todo aquello que pueda llegar a molestarnos (o asustarnos).

Visto como una totalidad, y aunque Salinas y Ayales digan lo contrario, el edificio legislativo anula cualquier idea de «transparencia» y parece estar pensado desde la imperiosa necesidad de no estar a la vista del Otro. La obsesión contemporánea con

\footnotetext{
${ }^{7}$ Isidro López y Emmanuel Rodríguez, «El modelo español», New Left Review 69 (2011), 5-26, https://newleftreview.es/issues/69/articles/isidro-lopez-emmanuel-rodriguez-el-modelo-espanol.pdf ${ }^{8}$ David Harvey, «La dialéctica», Territorios, 39, 245-272, https://revistas.urosario.edu.co/xml/357/35755981011/index.html
} 
la idea de transparencia se revela como lo que realmente es: una contradictoria opacidad.

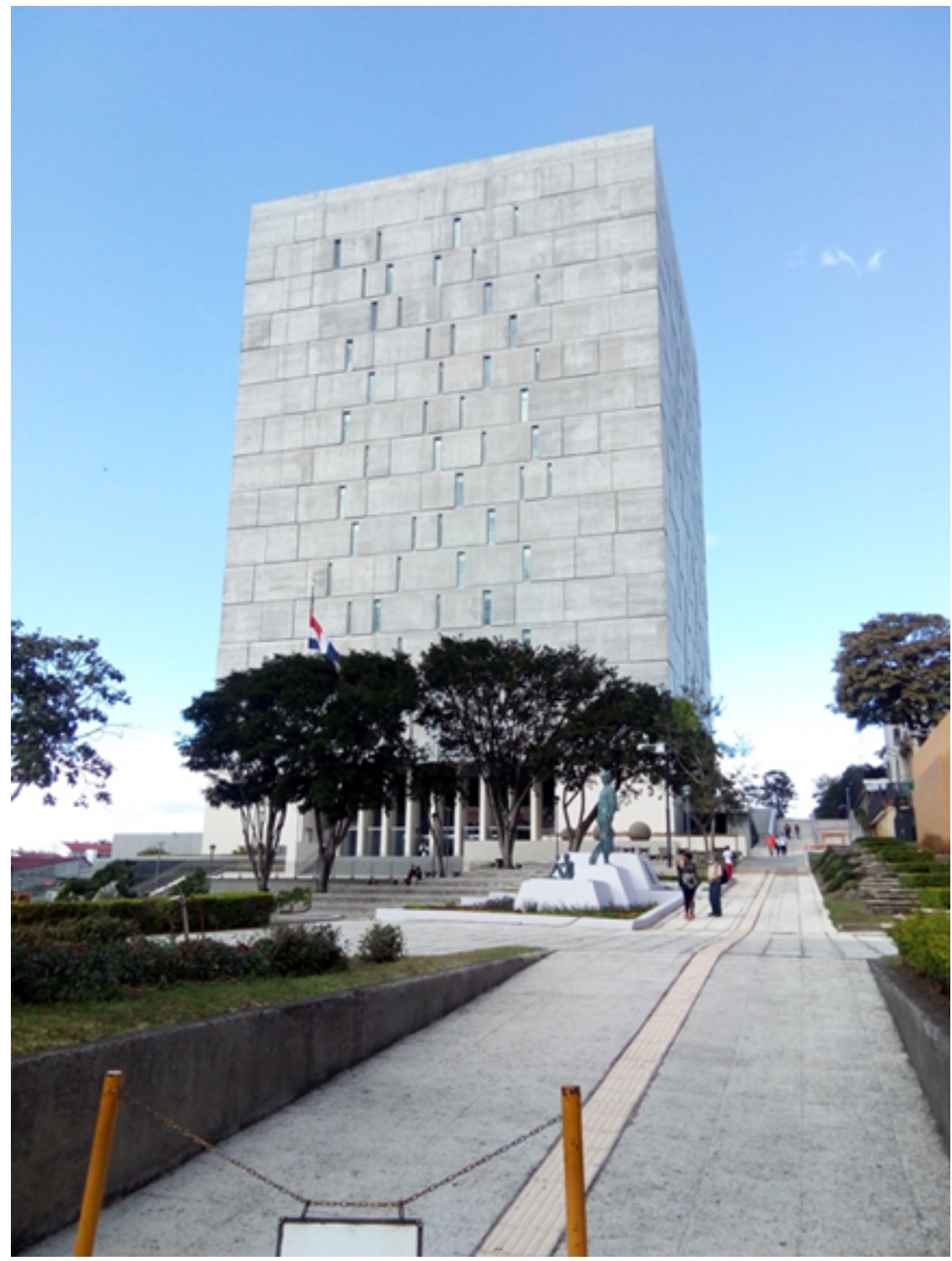

Panorámica de la fachada principal del edificio legislativo. Fotografía de la autora.

\section{La pulcritud del gesto y la palabra: ese feroz espejismo}

La asepsia del edificio, como la asepsia del verbo, se traduce en hechos concretos que ya hemos descrito: materiales y acabados de primera calidad conscientemente escogidos para evitar conductas indecorosas y antidemocráticas como rayar paredes e increpar a las personas diputadas. El objetivo, ya lo dijimos más arriba, es desarticular cualquier amago de conflicto, sofocar el disenso y establecer como normalidad una distancia preventiva entre las personas diputadas y la ciudadanía. 
La mesura y la desmesura, ese dilema que tanto les roba el sueño a los demócratas ejemplares, nos lleva a otro tema central. Hoy en día, tal como plantea el arquitecto Francesco Careri, «la única categoría con la que se diseñan las ciudades es la seguridad ${ }^{9}$, y el edificio de la Asamblea Legislativa, al igual que el montón de condominios amurallados que pululan en la GAM, parece confirmar esa tendencia.

Resguardar la seguridad de las personas diputadas le ha costado al país, en medio de una crisis fiscal sin precedentes y los estragos socioeconómicos derivados de una pandemia, la nada despreciable suma de 87 mil millones de colones, cifra que, según mencionó el mismo Ayales en algún momento, disparó el presupuesto legislativo en un $30 \%$.

La obsesión con el tema de la seguridad pone en evidencia varias cosas; entre ellas, el rotundo fracaso de nuestras clases gobernantes, élites que han sido sucesivamente incapaces de pensar y construir la ciudad (y el país) en función de un principio fundamental: la democratización del espacio y, ligado a ello, la erradicación de las profundas desigualdades que, alimentadas por el paulatino desmantelamiento del Estado social de derecho, están falseando las bases que le permitieron al país alcanzar importantes índices de desarrollo humano en un determinado momento.

El edificio de la Asamblea Legislativa no solo refleja a la perfección el solipsismo de una sociedad cada vez más encerrada en sí misma; también nos recuerda que entregar la responsabilidad de imaginar, gestionar y producir espacios e infraestructura pública a las empresas constructoras, firmas inmobiliarias y estudios privados de arquitectos revela algo que ya intuíamos desde hace tiempo: el Estado es, cada vez más, un cascarón vacío sometido a las exigencias de dos grandes fuerzas: los intereses económicos de grupos muy específicos y los vaivenes del mercado.

El lugar de los «estadistas» ha sido paulatinamente ocupado por una casta muy selecta de tecnócratas, y el espacio de lo político ha sido reconfigurado a partir de una sensibilidad que busca replicar la lógica del mundo privado.

El espacio, decía Henri Lefebvre, «no es un accidente de la materia, sino un resultado directo de la producción material». En línea con él, el fallecido geógrafo marxista Neil Smith señalaba algo que sigue siendo fundamental: «No se trata solo de que espacio y sociedad 'interactúen', sino que una lógica histórica específica (aquella de la acumulación de capital) guía la dialéctica histórica entre ellas» ${ }^{10}$.

La lógica histórica desde la cual se diseña un edificio que alberga el primer poder de la República de un país como el nuestro tendría, creo yo, que diferenciarse de la lógica desde la cual se diseña un condominio vertical como Urban Escalante o cualquier torrecita de Grupo Inmobiliario El Parque. Segregación y fragmentación social disfrazadas de modernidad y glamur, me parece, no tendrían que ser los principios ideológicos, estructurales y estéticos de un edificio que -se suponealberga a un poder de la República, uno que aspira a ser la «casa de la democracia».

El orden visual, cualquiera, siempre deja una impronta en las personas ciudadanas (peatones y peatonas) y lo conduce a mirar de una manera, a circular de una manera. El diseño del espacio facilita o dificulta formas de circulación $y$, al hacerlo, promueve o limita determinados comportamientos. En eso, justamente, este edificio

\footnotetext{
${ }^{9}$ Francesco Careri, Walkscapes (Barcelona: Editorial Gustavo Gili, 2013).

${ }^{10}$ Neil Smith, Desarrollo desigual. Naturaleza, capital y la producción del espacio (Madrid: Traficantes de sueños, 2020), 114.
} 
nos recuerda mucho al demócrata ejemplar, ese personaje que, investido de la legitimidad que le otorgan su intachable trayectoria y la validación que permanentemente recibe de parte de otros demócratas -igual o más ejemplares que él- y de influyentes medios de comunicación, también nos exhorta a circular de cierta manera en los centenarios pasillos de la democracia.

El dique de lo democrático está dado por las leyes, los consensos y las instituciones, pero también por las consignas y las prescripciones de estos grandes patriarcas del discurso democrático, quienes trazan sin titubeos el rumbo a seguir. Ellos son el faro, la mesura, la lucidez: la élite pensante a través de la cual se expresa una moral superior que, por supuesto, anhela incidir en la opinión pública y modelar el comportamiento ciudadano.

Incidir y modelar, esos dos verbos, me llevan de vuelta a Richard Sennett y a su insistencia en la idea de que la geometría (él se refiere específicamente a la geometría del espacio romano) era muy efectiva en transmitir su disciplina al movimiento corporal: «comunicaba la orden de mirar y obedecer» ${ }^{11}$.

¿De qué manera el movimiento corporal y el transitar por la ciudad [de San José] se ven condicionados por aspectos aparentemente anodinos como el volumen y el diseño de los edificios, el ancho de las calles y las aceras, la cantidad de rótulos que se balancean sobre nuestras cabezas, la ausencia o la presencia de automóviles, la calidad del alumbrado público, la intensidad del ruido y la cantidad de basura con la que lidiamos diariamente? ¿Qué implicaciones tiene la presencia o ausencia de ventanas para quienes trabajan dentro de un edificio y para quienes observan ese mismo edificio desde afuera? ¿Por qué se deja pasar el aire a través de celosías y sistemas de ventilación natural, pero la mirada de las personas diputadas es administrada con tanta cautela y austeridad? ¿Por qué se encuadra la ciudad de esa manera? ¿Qué sentido tiene estar en la ciudad si no nos es dado aprehenderla de alguna forma? ¿Por qué cercenar el paisaje exterior (la ciudad de San José) con tanta meticulosidad? ¿Por qué, a fin de cuentas, temerle a San José? ¿Por qué ocultar, proteger y «sepultar» los cuerpos de las personas diputadas bajo 20 pisos de concreto? ¿De qué o de quiénes se les está «protegiendo» y por qué? ¿Por qué diseñar un edificio institucional tomando como punto de partida el miedo al Otro?

El asunto de las ventanas, por cierto, desató en su momento interesantes polémicas, pero el señor Ricardo Ayales, director ejecutivo de la Asamblea Legislativa y férreo defensor del edificio, salió al paso con una intervención magistral:

Por supuesto que tiene ventanas ${ }^{12}$. Criticar siempre ha sido lo más fácil, construir lo más difícil. El costado oeste de ese edificio prácticamente está abierto, tiene un ventanal completamente abierto por donde ilumina todo el sol de la tarde el edificio. Es un efecto muy bonito, que cuando eso esté inaugurado, yo quiero ver al país; yo quiero ver a los que ahora son críticos, qué van a decir ahora. Este edificio es un orgullo para este país, es más, me atrevo a decir que es el edificio más importante que se ha construido desde la fundación de la República en este país.

\footnotetext{
${ }^{11}$ Sennett, Carne y piedra..., 79.

${ }^{12}$ Declaraciones brindadas por el Sr. Ricardo Ayales a Noticias Repretel. Corresponden a una nota titulada «Nuevo edificio de la Asamblea Legislativa dispara presupuesto» del 5 de setiembre del 2019, disponible en https://www.repretel.com/noticia/nuevo-edificio-de-la-asamblea-legislativadispara-presupuesto-2020/
} 
(...) el edificio de la Asamblea no es un centro comercial; esto no es un asunto de exhibición, es un parlamento y eso hay que entenderlo. Y este es un diseño adecuado y el país se va a dar cuenta cuando esté terminado.

El señor Ayales tiene toda la razón al decir que el edificio de la Asamblea Legislativa no es un centro comercial; incluso, podría concederle que es el inmueble más importante desde la fundación de la República, pero se equivoca rotundamente en algo: por cualquier lugar desde donde se mire, este edificio, como cualquier edificio institucional, es un asunto de exhibición: no solo es la puesta en escena de una serie de ideas muy puntuales respecto a lo que significa ser (ser persona diputada y ser persona ciudadana), sino que es la exhibición de un principio esencial para los demócratas ejemplares y las élites políticas del país: la verticalidad del poder.

El edificio, en tanto objeto inmerso en un espacio y una época, evoca una praxis muy específica de la democracia.

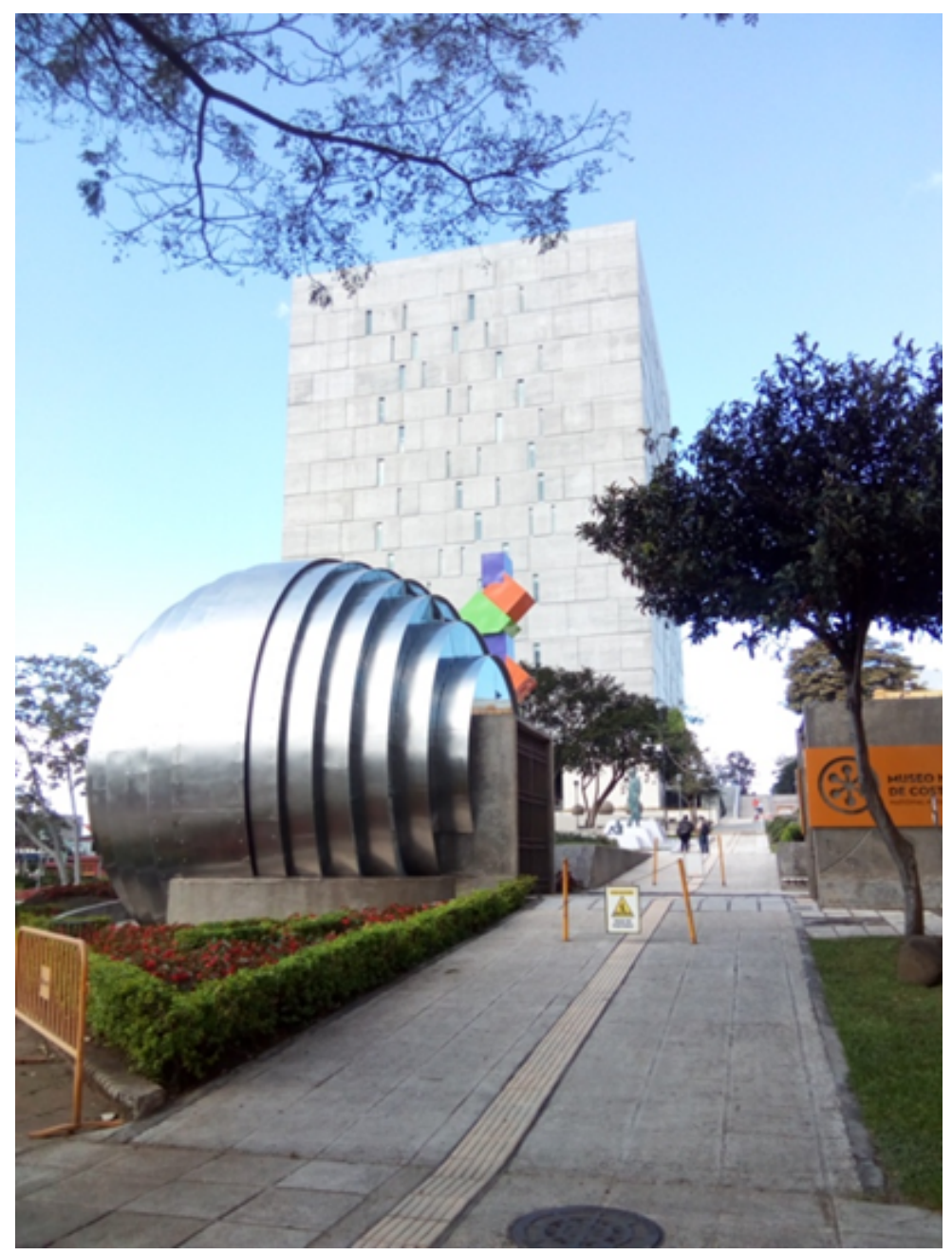

Panorámica de la fachada principal del edificio legislativo desde el costado del Museo Nacional. Fotografía de la autora. 


\section{En la carne y en la piedra todo es representación}

Veintiún pisos más abajo de una azotea con jardineras de concreto y árboles raquíticos que, dice Salinas, representan la «importancia de la naturaleza», caemos en una hondonada que representa «las raíces de la democracia». Ahí, en ese espacio rectangular, se amontonan las curules desde donde emerge, según él, la democracia costarricense: «Las raíces, representadas por el Plenario Legislativo, están por debajo porque las personas diputadas están por debajo del pueblo al que deben obedecer. Además, el plenario hace referencia a las raíces, porque se contará con diferentes esferas precolombinas».

¿Qué hay en el subsuelo de la democracia costarricense? Además de «raíces» y esferas precolombinas, como dice el arquitecto Salinas, estoy convencida de que ese espacio custodiado con tantísimo esmero es una fuente inagotable de las más espectaculares e inverosímiles epifanías. La primera y más llamativa fue la de la silla de un millón y medio de colones que a escasos días de haberse estrenado fue despedazada por el portentoso nalgatorio de un diputado ${ }^{13}$.

¿Qué clase de descalabro estructural se anuncia cuando las nalgas de un padre de la patria despedazan una silla de un millón y medio de colones que no lleva ni un mes de haberse colocado en el nuevo recinto legislativo? ¿Qué representan esa silla, ese diputado y la inmunidad parlamentaria que protege a esas nalgas en el continuum histórico de nuestra bicentenaria democracia? ¿Qué decir de los sermones ${ }^{14}$, los baños desbordados ${ }^{15}$, los pisos exteriores hundidos ${ }^{16}$, las diputadas perdidas en el purgatorio de ascensores y pasillos sin señalética ${ }^{17}$ y esa horrorosa placa conmemorativa repleta de errores ortográficos? ${ }^{18}$ ¿Qué decir de ese conjunto de llamativos y extraordinarios desastres que han marcado los primeros meses del nuevo edificio legislativo? ¿Qué tanto afectan esos descalabros estructurales y simbólicos la adecuada puesta en escena de lo democrático? ¿Afectan la puesta en escena o, más bien, la hacen verosímil, la «humanizan»?

Encima está el acceso principal, que está acompañado por una plaza donde los ciudadanos podrán transitar libremente. Esto representa la democracia y la libertad, donde se combinan los espacios urbanos con los del edificio. En

\footnotetext{
${ }^{13}$ Bahrley Quirós, «Silla de diputado que vale 1, 4 millones ya se quebró. No tiene ni un mes de uso», Diario Extra, 3 de noviembre del 2020, acceso: 4 de noviembre del 2020, https://www.diarioextra.com/Noticia/detalle/432559/silla-de-diputado-que-vale-1-4-mills-ya-sequebr-

${ }^{14}$ Wendy Pérez, «Inauguran nuevo plenario legislativo con bendición de arzobispo y pastora», El mundo.cr, 19 de octubre del 2020, acceso: 20 de octubre del 2020, https:/www.elmundo.cr/costarica/inauguran-nuevo-plenario-legislativo-con-bendicion-de-arzobispo-y-pastora/

15 Javier Paniagua, «Baños de la Asamblea tendrán que ser destaqueados tras desbordarse», crhoy.com, 11 de enero de 2021, acceso: 12 de enero del 2021,

https://www.crhoy.com/nacionales/banos-en-la-asamblea-tendran-que-ser-destaqueados-trasdesbordarse/

${ }^{16}$ Esteban Arrieta, «Nuevo edificio legislativo se agrieta y se hunde», La República.net, 5 de noviembre del 2020, acceso: 6 de noviembre del 2020, https://www.larepublica.net/noticia/nuevoedificio-legislativo-se-agrieta-y-se-hunde

${ }^{17}$ Paula Ruiz, «Diputada Marulin Azofeifa: 'Yo sí que me siento muy perdida en este edificio (...) imagínese las personas con discapacidad'», El Observador.cr, 11 de noviembre del 2020, acceso: 13 de noviembre del 2020, https://observador.cr/video-diputada-marulin-azofeifa-yo-si-me-siento-muyperdida-en-este-edificio-imaginese-las-personas-con-discapacidad/

${ }_{18}$ Alexánder Ramírez, «Placa del nuevo edificio legislativo sigue llena de errores ortográficos», crhoy.com, 24 de febrero del 2021, acceso: 26 de febrero del 2021, https://www.crhoy.com/nacionales/placa-del-nuevo-edificio-legislativo-sigue-llena-de-erroresortograficos/
} 
la parte superior se encuentra el edificio, que albergará las oficinas. Deja un hueco en el centro, para un patio central. Al lado de este cuenta con diez grandes ventanales, uno por piso, lo que dará gran luminosidad y frescura a todo el inmueble. Los ventanales miden 3,5 metros de altura por 20 metros de largo, con lo que se busca reflejar la transparencia del quehacer legislativo. La fachada representa la solidez centenaria de nuestra democracia (el destacado es de la autora).

«La fachada representa la solidez centenaria de nuestra democracia», afirma Salinas, pero ¿qué nos dice la fachada de ese edificio intelectual? ¿Qué comunica la fachada de este santuario de la democracia? ¿Dice algo? ¿Dice nada? ¿Por qué el concreto expuesto en estructuras de gran volumen debe ser entendido como un sinónimo de «solidez»? ¿Qué idea de democracia se materializa a través del concreto impoluto de esa fachada, de su monumentalidad, de su afectada «sobriedad»? ¿Por qué el proyecto se trabajó en esa escala particular? ¿Cuál concepto de ciudadanía y soberanía se desprende del diseño? ¿Qué papel otorga el edificio a la circulación de las personas? ¿Cuáles espacios son permitidos y cuáles le han sido vedados a la persona ciudadana, al peatón y a la peatona? y, en fin, ¿qué tipo de geometría se nos impone? ¿Por qué esa y no otra?

Considero que la máxima de que en el subsuelo y en la azotea de la democracia todo es representación aplica también para los demócratas ejemplares. En ellos y sus discursos, tal como sucede en el nuevo edificio legislativo, todo -al menos en apariencia- está impecablemente ordenado, limpio y bien dispuesto. Nada de hibris, nada de excesos.

Asombrosamente apolíneos, admirablemente cuerdos, aterradoramente sensatos. Detentores del rigor metodológico, apologetas de la comprobación de noticias, enemigos acérrimos del populismo. Rectos como jabalinas, los demócratas ejemplares asumen, por amor a sí mismos y a la patria, la cruzada más noble de todas: la de embestir la barbarie ajena y erigirse en voceros de la sensatez y del bien. Y en buena hora que así sea: el ideal democrático exige pilares firmes o, en su defecto, enhiestos varones capaces de defender las eternamente frágiles columnas de la democracia. Los espejismos de la verdad producen sus propios caballeros, y los caballeros, sus propias lanzas. Así ha funcionado, desde tiempos inmemoriales, el masculino y virtuoso círculo de la democracia.

Los demócratas ejemplares, esos habilísimos prestidigitadores del discurso, defienden la razón, la ciencia, la verdad, la justicia, pero frecuentemente pasan por alto que la razón, como todo lo humano, está atravesada de pulsiones y estulticia. Olvidan que los edificios de la coherencia se sostienen en el barro de las contradicciones y que las grietas suelen ser consustanciales a los edificios. Combaten el autoritarismo con todas sus fuerzas, pero secretamente, tal y como nos pasa a todos los seres humanos, fantasean con él, y a veces, más a menudo de lo que desearían, les produce un enorme placer la posibilidad de ejercerlo. Sucede -ya se intuye a lo que voy-, que ellos, como todo el resto de las personas que habitamos este mundo, sucumben -sucumbimos- ante las prácticas deleznables que tanto criticamos.

¿Qué sucede cuando las luces se apagan? ¿Cuál es el punto ciego de esa puesta en escena tan depurada que nuestros demócratas ejemplares desarrollan día a día por el bien del país y de sí mismos? 


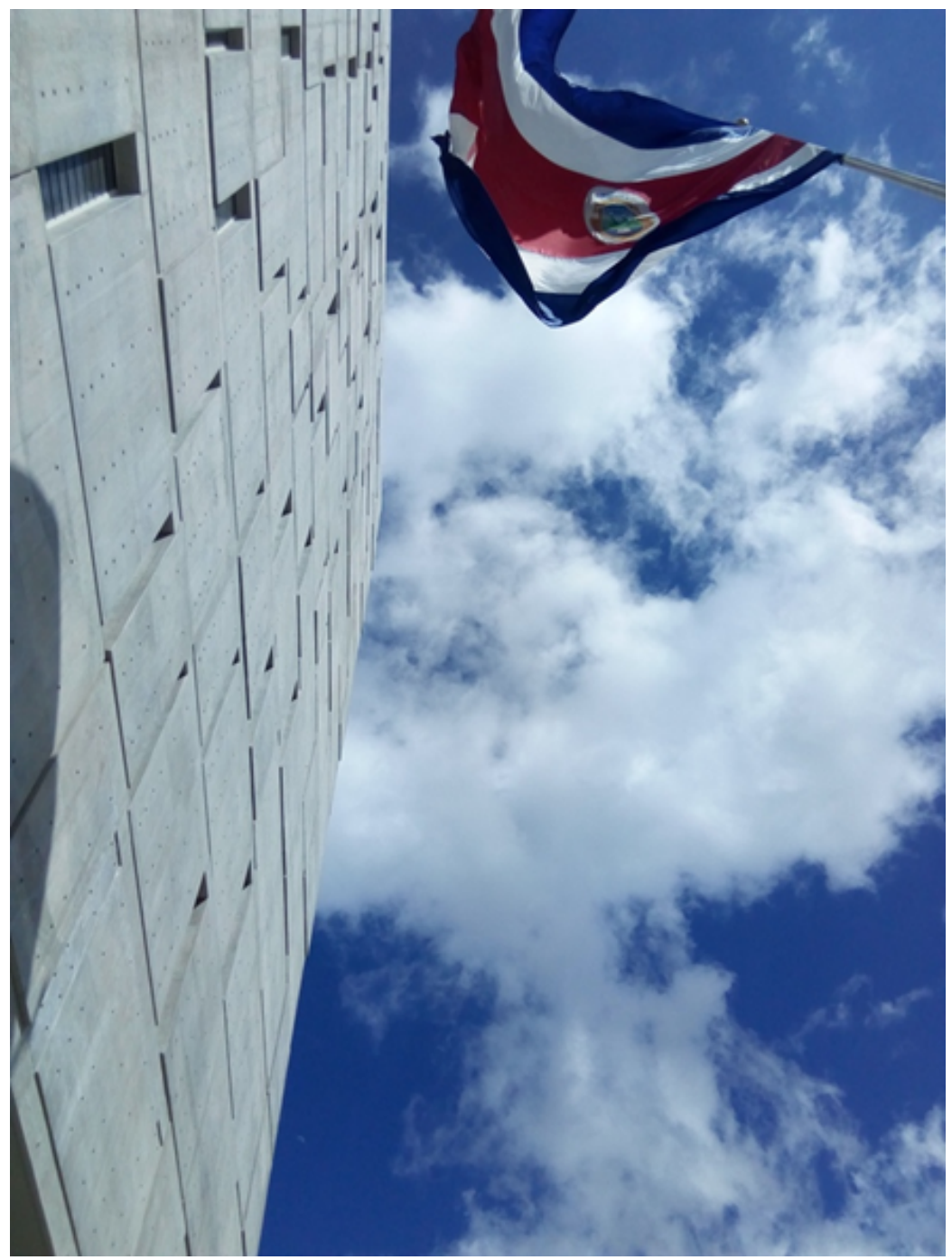

Detalle de la fachada principal del nuevo edificio legislativo. Fotografía de la autora.

\section{Lo grande, lo excelso: el delirio identitario convertido en edificio}

Aunque ya es momento de ir cerrando este largo recorrido, me parece importante dejar sugerida y abierta una reflexión en torno a ciertos aspectos identitarios y al modo en que se expresan en el nuevo edificio de la Asamblea Legislativa.

Subrayemos, en primer lugar, que la cantidad de recursos invertidos en el edificio legislativo, que exceden la capacidad presupuestaria de una economía quebrada como la nuestra, es coherente con una conducta muy extendida en nuestro país: la de empeñar lo que no se tiene para cumplir con ciertas aspiraciones y expectativas de clase; conducta que, por cierto, se suele criticar con especial hostilidad cuando son las clases trabajadoras y más empobrecidas las que incurren en ella (pensemos en la pantalla plana y el carro último modelo frente a una casa modesta en un barrio popular), no así cuando dicha conducta proviene de las clases medias y altas, pues, 
se supone, estas últimas tienen los medios económicos para financiar sus prácticas excesivas de consumo.

Las élites, así ha sido siempre, tienen derechos adquiridos cuando se trata de ostentar bienes o capital cultural, no así las clases empobrecidas, cuyo único derecho inalienable es el de seguir siendo pobres.

El nuevo edificio de la Asamblea es una invitación a pensar seriamente este asunto de la ostentación y, puntualmente, la correspondencia (o la relación patológica) entre lo que somos - como individuos, como país-y aquello a lo que aspiramos. El edificio legislativo, en su evidente desproporción, nos devuelve la imagen atrofiada de lo que somos, y esto, creo yo, es muy digno de reconocer. Es, por decirlo de alguna forma, un espejo que nos muestra claramente los delirios identitarios que padecemos y la disociación fundamental que da base a nuestra configuración.

En ese sentido, y esto hay que dejarlo muy claro, el nuevo edificio legislativo es un ejemplo de absoluta coherencia; es una celebración de las aspiraciones y el gusto de una clase social que podríamos catalogar como lumpen político, ese variopinto y decadente grupo de personas diputadas que, con muy honrosas y contadas excepciones, ha hecho de la Asamblea Legislativa una especie de púlpito desde donde ataca, sin pudores ni reservas, las bases del Estado social de derecho.

Se trata, pues, de un diseño que honra la decadencia política del bicentenario y que, además, no escatima en recursos para alimentarla y fortalecerla. Además, y muy a tono con los tiempos y las aspiraciones de clase de ese lumpen político, estamos frente a un caso clarísimo en donde importa más el nombre del arquitecto que la calidad y funcionalidad de la obra construida. Al arquitecto, en tanto «artista», se le permite y se le justifica todo, o casi todo.

Por último, ahora sí, desearía señalar que el nuevo edificio de la Asamblea constituye, al igual que la mansión del famoso «Manzanita» en la ciudadela León XIII, un hito en la construcción vertical contemporánea costarricense. La casa de «Manzanita» y el edificio legislativo son, salvando las distancias, símbolos de una determinada idea de hacer política. Ilustran perfectamente los tiempos que corren y son, a fin de cuentas, las dos caras de una estética bastante similar.

Uno negro, el otro blanco, con acabados de lujo y ubicaciones diametralmente opuestas en el casco urbano, evocan inversiones económicas totalmente salidas de contexto. Además, y quizás esto sea lo más interesante de todo, ofrecen una idea bastante clara del gusto y las aspiraciones de los grupos políticos y económicos que mueven los destinos de nuestro país en el año del bicentenario.

Formato de citación según APA

Flores-Valle, L. (2021). Mirar y obedecer: la estética autoritaria del nuevo edificio legislativo. Revista Espiga, 20 (42), 140-156.

Formato de citación según Chicago-Deusto

Flores-Valle, Laura. «Mirar y obedecer: la estética autoritaria del nuevo edificio legislativo». Revista Espiga 20, n. ${ }^{\circ} 42$ (setiembre, 2021): 140-156. 


\section{Referencias}

Arrieta, Esteban. «Nuevo edificio legislativo se agrieta y se hunde». $L a$ República.net, 5 de noviembre de 2020. Acceso: 6 de noviembre del 2020. https://www.larepublica.net/noticia/nuevo-edificio-legislativo-se-agrieta-yse-hunde

Careri, Francesco. Walkscapes. Barcelona: Editorial Gustavo Gili, 2013.

Harvey, David. Justicia, naturaleza y la geografia de la diferencia. Madrid: Traficantes de sueños, 2018.

Hidalgo, Rodrigo y Michael Janoschka, eds. La ciudad neoliberal: gentrificación y exclusión en Santiago de Chile, Buenos Aires, Ciudad de México y Madrid. Santiago: Pontificia Universidad Católica de Chile, 2014.

López, Isidro y Emmanuel Rodríguez. «El modelo español». New Left Review 69 (2011): 5-26. https://newleftreview.es/issues/69/articles/isidro-lopezemmanuel-rodriguez-el-modelo-espanol.pdf

Paniagua, Javier. «Baños de la Asamblea tendrán que ser destaqueados tras desbordarse». crhoy.com, 11 de enero de 2021. Acceso: 12 de enero de 2021. https://www.crhoy.com/nacionales/banos-en-la-asamblea-tendranque-ser-destaqueados-tras-desbordarse/

Pérez, Wendy. «Inauguran nuevo plenario legislativo con bendición de arzobispo y pastora». El mundo.cr, 19 de octubre de 2020. Acceso: 20 de octubre de 2020. https://www.elmundo.cr/costa-rica/inauguran-nuevo-plenariolegislativo-con-bendicion-de-arzobispo-y-pastora/

Pomareda, Fabiola. «Remueven láminas de zinc que rodeaban nuevo edificio de la Asamblea Legislativa». Semanario Universidad, 18 de enero de 2021. Acceso: 19 de enero del 2021. https://semanariouniversidad.com/pais/remueven-latas-de-zinc-querodeaban-nuevo-edificio-de-la-asamblea-legislativa/

Quirós, Bharley. «Silla de diputado que vale 1, 4 millones ya se quebró. No tiene ni un mes de uso». Diario Extra, 3 de noviembre del 2020. Acceso: 4 de noviembre del 2020.

https://www.diarioextra.com/Noticia/detalle/432559/silla-de-diputado-quevale-1-4-mills-ya-se-quebr-

Ramírez, Alexánder. «Placa del nuevo edificio legislativo sigue llena de errores ortográficos». crhoy.com, 24 de febrero del 2021. Acceso: 26 de febrero del 2021. https://www.crhoy.com/nacionales/placa-del-nuevo-edificiolegislativo-sigue-1lena-de-errores-ortograficos/ 
Ruiz, Paula. «Nuevo edificio legislativo está resguardado con material antigrafitis y póliza contra vandalismo». El Observador.cr, 25 de octubre 2020. Acceso: 30 de octubre de 2020. https://observador.cr/domingo-nuevoedificio-legislativo-esta-resguardado-con-material-antigrafiti-y-polizacontra-vandalismo/

Ruiz, Paula. «Diputada Marulin Azofeifa: 'Yo sí que me siento muy perdida en este edificio (...) imagínese las personas con discapacidad'». $E l$ Observador.cr, 11 de noviembre de 2020. Acceso: 12 de noviembre de 2020. https://observador.cr/video-diputada-marulin-azofeifa-yo-si-mesiento-muy-perdida-en-este-edificio-imaginese-las-personas-condiscapacidad/

Sennett, Richard. Carne y piedra. El cuerpo y la ciudad en la civilización occidental. Madrid: Alianza Editorial, 2019.

Smith, Neil. Desarrollo desigual. Naturaleza, capital y la producción del espacio. Madrid: Traficantes de sueños, 2020. 